\title{
O curso de Pedagogia e a formação de educadores ${ }^{1}$
}

\author{
Dermeval Saviani*
}

Palavras-chave: Saviani, Dermeval - Entrevistas.

Key words: Saviani, Dermeval - Interviews.

Revista Perspectiva: Professor, a temática sobre a qual o convidamos para esta entrevista refere-se à Resolução CNE/CP n ${ }^{\circ} 1 / 06$, de 2006. ${ }^{2}$ Gostaríamos de conhecer sua avaliação dessa reforma do Curso de Pedagogia e dos rumos que poderá tomar depois dela. Também nos interessa saber por que o senhor se manteve distante do debate que envolveu inúmeros intelectuais da área.

Dermeval Saviani: Eu participei do início do processo, em 1980 , na $1^{\text {a }}$ Conferência Brasileira de Educação, ${ }^{3}$ quando foi organizado o primeiro simpósio sobre a formação do educador, no qual surgiu o "Comitê Pró-participação na Reformulação dos Cursos de Pedagogia e de Licenciatura". Depois, acabei não podendo ficar diretamente envolvido na organização do processo e acabei me distanciando. Acompanhei à distância, participei de algumas discussões como convidado, mas não fiz parte diretamente de todo o processo. Quando começou o novo governo, ${ }^{4}$ em 1994, e no MEC ficou o Paulo Renato, ${ }^{5}$ o próprio debate da LDB entrou na reta final. ${ }^{6}$ Acompanhei o processo, elaborei um artigo com um anteprojeto de LDB que, por sinal, se converteu no projeto original da Câmara dos Deputados, fiz muitas palestras sobre a LDB, analisei, publiquei um livro ${ }^{7}$ imediatamente após a aprovação da nova LDB. Mas não participei diretamente do processo em relação ao Curso de Pedagogia.

Revista Perspectiva: E a que se deveu esse afastamento?

Dermeval Saviani: De um lado, por que não fui convidado para tomar decisões mais diretas e, de outro, por que também entendi, como um analista, como alguém que estava estudando os processos, que deveria manter distância. Outro elemento é que eu discordava radicalmente da proposta educacional do gover-

\footnotetext{
* Doutor em Filosofia da Educação pela Pontifícia Universidade Católica de São Paulo. Professor aposentado da Universidade Estadual de Campinas. É Professor Emérito da UNICAMP e Coordenador Geral do Grupo de Estudos e Pesquisas "História, Sociedade e Educação no Brasil” (HISTEDBR).
} 
no FHC e não poderia participar do processo enquanto formulação de políticas. Enquanto movimento crítico, participei. Tive participação ativa nos Congressos Brasileiros de Educação, de modo especial em 1997, na elaboração da proposta de Plano Nacional de Educação, tendo publicado já em 1998 o livro Da nova LDB ao novo Plano Nacional de Educação. No caso da Pedagogia, quando começou a formulação das Diretrizes Nacionais eu não estava fazendo parte do Conselho Nacional de Educação e também não integrava as diretorias das entidades. Por isso, acompanhei à distância. Quando surgiu a primeira proposta das diretrizes do $\mathrm{CNE}^{8}$ eu, tomando conhecimento dela, escrevi sobre o seu caráter e, em seguida, me manifestei via e-mail para a Helena que sempre se manteve mais ou menos na direção da ANFOPE, ${ }^{9}$ perguntando o que era aquilo e fazendo algumas críticas, pois me parecia que a referida proposta acabava por reduzir o curso de pedagogia ao normal superior. Helena deu retorno dizendo que era possível revertê-la. Aí veio a mobilização da ANFOPE, ANPEd, FORUNDIR ${ }^{10}$ com uma nova proposta; dei uma olhada na proposta que resgatava um pouco a história do curso e continha dispositivos que melhoravam sensivelmente o texto gestado no CNE. Mas eu não tinha condições, até por falta de tempo, de priorizar essa atividade e assumir o compromisso de participar mais diretamente. Finalmente houve a aprovação das DCNP e tomei conhecimento na medida em que as coisas aconteciam. Nunca fui chamado a participar mais diretamente, o que não me impedia, é claro, de tomar a iniciativa de conversar com as pessoas e encaminhar contribuições para o processo de elaboração das referidas diretrizes. De fato, porém, estou sempre envolvido com muitas coisas e acossado por solicitações dos mais diferentes tipos, não tendo condições de me envolver em todas as iniciativas do campo da educação. A razão decisiva, porém, é que, avaliando o processo de uma posição externa àquela mobilização, eu notava que era muito difícil reverter aquela situação.

Revista Perspectiva: Professor, tendo em vista o resultado a que se chegou, qual sua posição?

Dermeval Saviani: Eu diria que o resultado final melhorou relativamente à proposta gestada em março de 2005 no Conselho Nacional de Educação, mas não é satisfatório. ${ }^{11}$ De um lado, por toda a história do processo e porque nós não fomos capazes de formular uma proposta mais consistente enquanto coletivo. De outro lado, ela não é satisfatória porque o contexto também não possibilita isso. O contexto social e político que nós atravessamos não tem possibilitado a emergência de alternativa mais sólida no que se refere à formação do educador, aí entendidos o professor de modo geral e o pedagogo em particular. Então, do ponto de vista dessa debilidade histórica - já disse isso em trabalhos anteriores e vou retomar - acho que o movimento pró-formação de educadores da década de 1970 sempre ficou muito preso a problemas de ordem organizacional. Isto é,

PERSPECTIVA, Florianópolis, v. 26, n. 2, 641-660, jul./dez. $2008 \quad$ http://www.perspectiva.ufsc.br 
na formulação de uma proposta de como organizar um curso dentro dos parâmetros que estão aí. Eu venho insistindo, já faz um tempo, na seguinte questão: a educação no país foi fortemente alterada com o regime militar, que introduziu mudanças de fundo na estrutura organizacional da educação do país. No caso do ensino superior nós temos a regulamentação de 1969, decorrente da Lei 5540, de 1968. ${ }^{12}$ Ela alterou o ensino superior fortemente baseada no modelo americano, adotando o sistema de créditos, matrícula por disciplina, cursos semestrais, departamentalização, separação entre ensino e pesquisa. Essas são conseqüências sérias que dizem respeito à qualidade, negativas a meu ver, do ensino superior. Coisas simples, como a própria questão do curso anual passar a semestral, têm impacto. O curso fica concentrado por semestre, fragmentado, com a matrícula por disciplina se perde a noção da classe, o professor só toma conhecimento da situação real dos seus alunos quando já se encaminha para o final de semestre. E tudo se encerra ali para recomeçar do zero no início do semestre seguinte com uma nova turma que pode ser formada por alunos de diferentes cursos. O professor não tem como acompanhar as dificuldades dos alunos e tomar medidas para saná-las. No curso anual e seriado era diferente porque a turma entrava e seguia até o final, até a formatura. E no curso anual o professor tinha a vantagem de ficar um ano junto aos alunos e com as férias de julho no meio. Para aqueles alunos que trabalhavam enquanto faziam o curso, especialmente os do noturno, e que tinham dificuldades de acompanhar e seguir todas as exigências que o professor fazia, havia as férias de julho, um momento em que, não precisando assistir aulas, eles podiam atualizar as leituras do semestre, podiam refazer trabalhos conforme o professor tinha orientado. E, ao retornar em agosto entregavam os trabalhos, o professor avaliava e podia dar o retorno: melhorou aqui, mas não melhorou lá, aqui ainda é preciso aprofundar, tem que sanar esse tipo de dificuldade etc. E o trabalho prosseguia durante todo o segundo semestre até a última avaliação no final de novembro e início de dezembro. Agora não. O professor toma contato com os alunos em março e quando começa a conhecê-los melhor, já está no final de abril ou início de maio. E quando começa a querer tomar as medidas para sanar as dificuldades detectadas, maio termina e chega o mês de junho quando já é necessário fazer a avaliação final. Ora, fez-se o tempo todo a crítica ao modelo implantado pela reforma universitária de 1968, fez-se a crítica às universidades, ao tecnicismo e tudo mais. Depois vieram outras propostas, como a do Grupo Executivo para a Reformulação do Ensino Superior (GERES) criado em 1986, pelo então Ministro da Educação, Marco Maciel, que introduziu a distinção entre universidades de pesquisa e universidades de ensino. Mas não se modificou a estrutura, não se discutiu a estrutura. Então, fala-se em reforma universitária, em reforma curricular, mas mantém-se a estrutura atual, sendo que essa estrutura é um óbice sério para uma educação mais qualitativa e para o encaminhamento da formação 
numa outra direção. Entendo que o movimento pró-reformulação do campo de formação de educadores também teve sua marca na retomada de certos pontos, mas nunca se aprofundavam essas questões. O que eu estou querendo dizer com isso? O que é um docente bem formado, o que é uma docência sólida e o que isso implica? O que é a base comum nacional? Esta era reiterada em todos os encontros, mas nunca se conseguiu uma definição efetiva.

Revista Perspectiva: A base comum nacional desapareceu nas DCNP, permanecendo apenas a base docente.

Dermeval Saviani: Mas está na LDB [Lei no 9394/96] (BRASIL, 1996). Ali se mantém a base comum nacional na formação dos profissionais da educação. $O$ educador será formado na pedagogia ou em nível de pós-graduação, garantida a base comum nacional (Art. 64). Esta era uma palavra de ordem do movimento e nas diretrizes ficou a base docente e a licenciatura e bacharelado transformaramse numa coisa só, embora as diretrizes camuflem um pouco porque falam do curso como uma licenciatura. Mas a queda da base comum nacional talvez tenha se dado porque nunca conseguimos uma definição positiva dela. Sabíamos que não era sinônimo da parte comum do currículo e nem de currículo mínimo; que não seria obtida por definição de algum colegiado; e que também não resultaria da elaboração de intelectuais que supostamente fossem especialistas na área e reconhecidos como tais. Ela deveria surgir do movimento, quer dizer do coletivo. Desse modo, a noção de "base comum nacional" permaneceu um tanto vaga e toda a força das propostas girou em torno da reorganização do curso, mantida a mesma estrutura. Então o curso continua sendo em média de quatro anos, em regime semestral, com matrícula por disciplinas. E formar a docência foi interpretado pelo movimento como formar professores para Educação Infantil e para os anos iniciais do Ensino Fundamental. Então era isso, as experiências se organizaram dessa forma. É isso que eu chamo de debilidade do movimento. A própria história do movimento dá indicativo de que não fomos capazes de elaborar uma proposta mais sólida. Venho insistindo - e já faz um certo tempo, desde a elaboração do texto "Contribuição a uma definição do curso de pedagogia", em 1971, ${ }^{13}$ passando em 1980 por aquele documento que está no caderno da $\mathrm{ANDE}^{14}$ e depois, oralmente, quando fazia palestras, e retomei agora em termos mais sistemáticos no projeto de pesquisa denominado "O espaço acadêmico da pedagogia no Brasil" - na necessidade de uma formação sólida em educação. Estou insistindo que o curso de pedagogia deveria ser um ambiente rico, intenso e exigente de estímulo intelectual, que retomasse os clássicos, acolhesse os jovens e os colocasse em processo de formação. Foi essa a minha contraposição à Indicação n.70, elaborada por Valnir Chagas ${ }^{15}$ e aprovada pelo Conselho Federal de Educação em 1975, que dizia que se deveria formar o especialista no professor. Fui muito claro nisso: 
em lugar de formar o especialista no professor eu propunha formar seja o especialista seja o professor no educador. Eu me contrapunha àquela idéia de Valnir Chagas de formar o especialista no professor que pressupunha, para ingresso no curso de formação de especialistas em educação, não apenas a conclusão de uma licenciatura anterior, mas experiência no magistério, no mínimo de dois anos. $\mathrm{Ou}$ seja, o interessado em realizar estudos superiores de educação teria que fazer um curso de licenciatura, se formar professor, lecionar dois anos e depois voltar para a universidade e se formar educador. Isso, na prática, situaria a formação do educador em nível de pós-graduação lato sensu, já que pressupunha uma licenciatura. Chagas, porém, considerando a existência de professores habilitados em nível de segundo grau que, portanto, possuíam o requisito da experiência prévia, situou a referida formação na própria graduação, definindo-a como habilitações que se acrescentam a uma licenciatura anterior. Mas deixou claro, no projeto de Resolução que se seguiu à Indicação, que "o nível natural de cultivo do pedagogo é o da pós-graduação". Não deixa de ser interessante observar que a LDB, ao mesmo tempo em que se propôs a elevar ao nível superior a formação dos professores dos anos iniciais da escolarização, manteve, no já mencionado artigo 64, a graduação em pedagogia como alternativa à pós-graduação para a formação dos profissionais da educação destinados a atuar na educação básica nos âmbitos da administração, planejamento, inspeção, supervisão e orientação educacional. Na época, o argumento que eu levantava para me contrapor ao Chagas era o seguinte: por que você tem que condicionar a formação do educador, do especialista a exercício profissional prévio se nenhuma carreira exige isso? Para um jovem ser engenheiro primeiro ele tem que fazer construções e depois fazer o curso? Eu dizia: assim como você encontra jovens querendo seguir a carreira de médico, de advogado, dentista, enfermeiro, entre outras, você tem também jovens interessados em aprofundar estudos no campo da educação, querendo ser educador, ser professor naquele sentido forte da palavra, não apenas de transmissor do conhecimento. Então, por que no caso dos jovens interessados em estudar educação terei que dizer: "você quer ser educador? Tudo bem, mas primeiro você vai estudar física, matemática ou qualquer outra matéria dos currículos escolares para se tornar professor, ficar dois anos lecionando e depois você volta aqui, na Faculdade de Educação”. Não. Não concordo com esse encaminhamento. Afinal, para que existe a Faculdade de Educação? Cabe-lhe, em lugar de dissuadir os jovens interessados na educação, acolhê-los imediatamente e colocá-los num ambiente rico e estimulante, envolvendo-os diretamente nas atividades de ensino, estudos e pesquisas. Com efeito, quanto mais cedo eles forem colocados num clima de intenso e exigente trabalho intelectual, num processo de aprofundamento de estudos sobre educação, tanto melhor. Só que o movimento desencadeado em 1980, por vias tortas, acabou se orientando por uma conduta semelhante à proposta de Valnir Chagas. Adotando a docência como base da formação do educador possibilitou, ao menos 
à primeira vista, a leitura de que para ser educador primeiro tem que ser professor. Aquele movimento lançado para combater o projeto de Chagas acabou adotando a própria tese por ele esposada.

Revista Perspectiva: E a que o senhor atribui essa mudança de rota? A impossibilidade de ser qualquer coisa antes de ser professor não estreitaria o campo da formação?

Dermeval Saviani: Talvez isso tenha relação com a questão da prática. A prática educativa é a base da formação do educador e essa prática foi compreendida como docência. O problema é que nunca se conseguiu definir exatamente de que se tratava. Docência se refere ao trabalho pedagógico que se desenvolve na relação entre o professor e o aluno nas escolas, geralmente nos espaços caracterizados como salas de aula? Ou se estende a múltiplos espaços de diferentes tipos? Isso abriu caminho para se entender a docência de uma forma um tanto caótica. Parece-me que o caos presente nessa tese da docência como base da formação do educador é a idéia de que a educação é um processo multifacetado que consiste na docência, mas a docência está ligada a um aspecto da visão majoritária, da educação formal, da educação escolar. Então desde o movimento da Escola Nova ${ }^{16}$ passando pelo movimento da UNESCO, com a proposta da educação permanente, vem se combatendo a concepção que liga a docência ao trabalho escolar, vista como uma característica da pedagogia tradicional, da educação como transmissão de conhecimento. Assim, pode se definir a docência como compatível a essa visão na medida em que se considera docência como prática educativa.

Revista Perspectiva: Ou seja, não se refere à prática restrita à sala de aula.

Dermeval Saviani: Coube, nesse processo, um debate que foi acirrado contra o Libâneo por conta daquela tese defendida por ele de que a sala de aula é o lugar privilegiado do trabalho didático. Então houve aquela discussão de que isso seria um reducionismo. No entanto, a ANFOPE abraçou a tese da docência como base da formação do educador, tese essa que veio a ser criticada exatamente por Libâneo ${ }^{17}$ como redutora da educação e, portanto, da pedagogia, cujo objeto não se reduz à docência. Daí, a objeção contra as Diretrizes Curriculares Nacionais do Curso de Pedagogia, de certo modo endossadas pela ANFOPE: tais diretrizes acabaram criando um curso para formar coisas que são diferentes, sendo-lhe impossível dar conta de todas elas. Entende-se que seria melhor manter o curso de Pedagogia formando o especialista em educação e criar um outro curso, de licenciatura, para formar professores para a Educação Infantil e para os anos iniciais do Ensino Fundamental, licenciaturas nos moldes das outras, já existentes, que formam professores para as séries finais do Ensino Fundamental e para o Ensino Médio. Minha posição se diferencia tanto daquela que se corporificou nas diretri- 
zes curriculares nacionais, com respaldo da ANFOPE, como daquela acima exposta, que defende dois cursos distintos, esposada pelo grupo liderado por Libâneo. Parto da constatação de que a escola na sociedade moderna se converteu no espaço por excelência da educação. O docente é, assim, educador por excelência porque é aquele que atua na instituição educativa para formar as novas gerações. Em conseqüência, a escola passou a ser a referência para as outras formas de educação, sendo valorizada pela família, pela sociedade e, até mesmo, por aqueles que são contra ela naquele sentido de ser formativa. Não há como barrar esse movimento. Até os neoliberais, os assistencialistas, que tentam transformar a escola num espaço de assistencialismo, não abrem mão da escola. Então, por esse ângulo poderia se defender a docência como base comum do educador e também perguntar qual é o educador que nós queremos formar. A meu ver esse educador seria exatamente o pedagogo, entendido como o especialista na organização dos processos educativos. E onde esses processos educativos são organizados de forma mais sistemática? É nas escolas. Decorre desse entendimento a posição que venho defendendo e que apresento tanto no tema em destaque sobre a pedagogia, ${ }^{18}$ que organizei para a Revista Cadernos de Pesquisa, da Fundação Carlos Chagas, como no livro $A$ pedagogia no Brasil: história e teoria. ${ }^{19}$ Nessa perspectiva não se torna tão complicado pensar o curso de Pedagogia articulando a formação do pedagogo, isto é, do especialista em educação, com a formação dos professores da Educação Infantil e dos anos iniciais do Ensino Fundamental. Mas para isso eu teria que tomar como campo de referência a escola. Tratar-se-ia, então, de formar o pedagogo ou o especialista da educação que tem o domínio da escola, isto é, da forma como a escola está constituída com seu currículo em pleno funcionamento. Assim, o pedagogo, ao dominar o modo como a escola funciona, estaria, sem dúvida, capacitado tanto para ministrar o ensino, como para coordenar as atividades didático-pedagógicas ou gerir o funcionamento da escola. Isso especialmente porque, no caso da educação infantil e das séries iniciais do ensino fundamental estamos diante de professores integrados e não parcelados, como ocorre com as quatro últimas séries do Ensino Fundamental e no Ensino Médio, nos quais estamos diante de professores especializados no conteúdo, o que implica outro modelo de professor. Aqui é preciso ter presente a existência de dois modelos para a formação do educador. Há um que chamo de "modelo dos conteúdos culturais cognitivos" e outro, o "modelo didático-pedagógico". Para o primeiro modelo o professor é aquele que domina os conteúdos das disciplinas; não há preocupação didático-pedagógica. A questão didático-pedagógica se resolve por conseqüência, na experiência prática, não sendo objeto de formação sistemática. Por isso, a universidade não vai se preocupar com esse tipo de coisa. Na universidade, via de regra, prevalece o entendimento de que o professor precisa dominar os objetos de ensino, ou seja, para ser professor de história tem que saber história, para ser 
professor de matemática tem que saber matemática, e assim por diante. O "como se ensina" decorreria do próprio conhecimento, conforme o princípio "quem sabe, ensina"; se aprendeu história, ele sabe ensinar história. Garantida a condição básica do "o que ensinar", o "como ensinar" será adquirido na própria prática, seguindo-se o princípio do "aprender fazendo", vigente no sistema das corporações de ofício. Diversamente, o modelo didático-pedagógico argumenta que o professor, para ser tal, necessita ter formação específica no aspecto didático-pedagógico. Tradicionalmente na história da educação européia o que presenciamos é o seguinte: a questão didático-pedagógica foi considerada como fazendo algum sentido para o professor primário, mas não para o professor secundário, muito menos para a formação do professor do ensino superior. Escrevi sobre isso no livro Formação de professores: a experiência internacional sob o olhar brasileiro. ${ }^{20}$ Uma outra hipótese que eu poderia levantar refere-se à pedagogia como campo epistemológico ligado à educação das crianças, consoante o significado etimológico do termo "pedagogia". Nesse âmbito foram organizadas as escolas normais de nível médio para formar professores primários segundo o modelo pedagógicodidático, prevendo-se também a criação de escolas normais superiores para formar professores secundários. Mas isso não funcionou na prática, porque as escolas normais superiores tanto na França como na Itália se transformaram em escolas de altos estudos, desvinculadas de qualquer preocupação de caráter pedagógico. No Brasil, com a nova LDB aprovada em dezembro de 1996, abriu-se a possibilidade da instalação de escolas normais superiores ${ }^{21}$ para formar o professor primário em nível superior, mantendo-se a formação dos professores secundários nos cursos de licenciatura. Estes continuam com o viés de cursos centrados no conteúdo acoplados, portanto, ao bacharelado. Na história da educação brasileira essas medidas remontam à iniciativa de Francisco Campos criando, em 1931, a figura da Faculdade de Educação, Ciências e Letras - que, entretanto, não vingou. ${ }^{22}$ Quando se criou a USP, em 1934, instituiu-se a Faculdade de Filosofia, Ciências e Letras e incorporou-se o Instituto de Educação decorrente da reforma Fernando de Azevedo de $1933 .^{23}$ Em 1935 criou-se a Universidade do Distrito Federal com uma Escola de Educação. ${ }^{24}$ Em 1938 encerra-se o Instituto de Educação da USP que é incorporado como Seção de Educação à Faculdade de Filosofia, Ciências e Letras. A partir daí vão ser criados os cursos de Pedagogia e de Didática segundo o modelo do decreto de $1939 .{ }^{25}$ Os cursos da Faculdade de Filosofia eram de estudos básicos, de caráter científico e desinteressado, devendo fundamentar todas as profissões. Faço aqui um parêntese: eu costumo dizer que o ensino superior é sempre profissionalizante, mesmo nos casos dos cursos que não têm uma destinação direta e imediatamente profissional. Um curso de hebraico, por exemplo, embora se possa admitir que seja procurado por jovens de origem judaica com o objetivo específico de manter a tradição de sua língua original, 
nós observamos que, no final, quando o aluno sai da universidade ele vai utilizar a formação recebida para fazer carreira diplomática, vai ser intérprete, tradutor de textos escritos em hebraico ou vai ser crítico literário especializado na literatura hebraica. Sua atividade profissional resulta daquele curso que aparentemente seria desinteressado não tendo, pois, uma destinação profissional determinada. Portanto, os cursos de nível superior desembocam sempre, de uma forma ou de outra, em algum tipo de formação profissional. Inversamente ao que ocorre com o Ensino Superior, o Ensino Fundamental nunca é profissionalizante. Quanto ao Ensino Médio, a reforma imposta pela Lei no 5692/71 pretendia torná-lo compulsoriamente profissionalizante, ${ }^{26}$ a reforma decorrente da Lei no 9394/96 (a nova LDB) reafirmou seu caráter propedêutico, desvinculando-o da formação profissional. ${ }^{27}$ No caso da Faculdade de Filosofia, Ciências e Letras em sua concepção original, ela teria caráter desinteressado, fornecendo a base científica para todos os demais cursos da universidade. Mas à medida que as faculdades profissionais não abriram mão de suas prerrogativas de formação, mantendo em seu interior as disciplinas de base científica, à Faculdade de Filosofia, Ciências e Letras coube a formação de professores para o ensino secundário.

Revista Perspectiva: Quando o curso de Pedagogia foi criado, em 1939, ele não era uma licenciatura. Para o pedagogo ser professor, tinha que fazer o curso de Didática, de um ano. Era o modelo bacharelado mais licenciatura, o chamado esquema $3+1$.

Dermeval Saviani: O aluno fazia três anos numa área específica e o curso de didática. Então era licenciado em História, em Letras etc. No caso da pedagogia também o aluno fazia três anos de um currículo específico, mais o curso de didática com a duração de um ano e era licenciado em quê? Ia lecionar onde? Nem mesmo nas escolas normais, porque a Lei Orgânica do Ensino Normal, de $1946,{ }^{28}$ não especificou que a condição para ser professor da escola normal era ter licenciatura em pedagogia. O pedagogo tinha que competir com os outros que também podiam lecionar lá pela tradição. Quem podia lecionar nas cadeiras das escolas normais que preparavam os professores primários eram os intelectuais da época, os profissionais de direito, medicina, engenharia. Também podiam lecionar os padres que tinham formação em teologia e filosofia, além dos demais licenciados da nova Faculdade de Filosofia, Ciências e Letras. O curso de Pedagogia só veio a se firmar depois, com a LDB 4.024/61, quando se configurou como curso que licenciava para o magistério das disciplinas pedagógicas das escolas normais.

Revista Perspectiva: Professor, retomando a questão da docência, para a ANFOPE a docência não seria a conjugação do professor e do especialista?

Dermeval Saviani: No movimento que surgiu em 1980 com o "Comitê próparticipação na reformulação dos cursos de pedagogia e licenciatura”, que de- 
sembocou na ANFOPE, desenvolveu-se um combate às especializações, porque eram vistas como tecnicistas; era a divisão de trabalho no campo pedagógico reproduzindo uma visão do processo produtivo tal como se dava nas fábricas. Havia o supervisor e o trabalhador que executava as tarefas; esses supervisores eram os agentes do patrão para impor seus interesses aos trabalhadores que executavam as tarefas nessa divisão de trabalho. A concepção era retirada dos que faziam e passada para quem dirigia. Reproduziu-se isso na educação e a forma com que se traduziu foi o advento do especialista. O professor foi desapropriado da concepção de seu trabalho que coube aos especialistas. De fato a lei ${ }^{29}$ teve um papel importante nessa reorganização da escola e da formação dos profissionais da educação. Enfatizou-se a questão do planejamento: tínhamos os pacotes com especificações e cada professor na sua disciplina tinha que preencher formulários segundo aquelas diretrizes emanadas dos órgãos de planejamento. A crítica aos especialistas assentava-se sobre o fato de que controlavam o processo e retiravam essa prerrogativa dos professores, os verdadeiros agentes do processo educativo. Nesse contexto, uma das principais direções assumidas pelas experiências de reformulação do curso de pedagogia foi a extinção das habilitações pedagógicas, centrando-se a organização curricular na formação de professores para a educação infantil e as primeiras séries do ensino fundamental, consoante o princípio da docência como base da formação do pedagogo. Portanto, respondendo diretamente à pergunta, eu diria que a concepção vigente na ANFOPE não implicava a conjugação do professor e do especialista. Talvez o que estava em causa fosse uma outra concepção de especialista em educação, uma outra concepção de pedagogo, cuja base seria a docência. Mas, como já afirmei, essa hipotética nova concepção em nenhum momento foi explicitada. Em contrapartida, como já assinalei antes, minha posição tem como base exatamente a conjugação entre a formação do pedagogo enquanto especialista da educação e o professor, admitindo que isso pode ser feito num mesmo curso, o de pedagogia, desde que este se volte para o modo de organização e funcionamento da educação escolar. Expressei essa posição na conclusão da segunda parte do livro A pedagogia no Brasil: história e teoria", nos seguintes termos:

Tomando a história como eixo da organização dos conteúdos curriculares e a escola como lócus privilegiado para o conhecimento do modo como se realiza o trabalho educativo será possível articular, num processo unificado, a formação dos novos pedagogos em suas várias modalidades. Por esse caminho poder-se-á atingir, ao mesmo tempo e no mesmo processo, os cinco objetivos previstos na Resolução que fixou as novas diretrizes curriculares para o Curso de Peda- 
gogia: a formação para o exercício da docência (1) na Educação Infantil, (2) nos anos iniciais do Ensino Fundamental, (3) nos cursos de Ensino Médio na modalidade Normal, (4) em cursos de Educação Profissional na área de serviços e apoio escolar, e (5) em outras áreas nas quais sejam previstos conhecimentos pedagógicos. E não apenas isso. Também a formação para as atividades de gestão e, portanto, o preparo inicial dos especialistas referidos no artigo 64 da LDB poderá ser contemplado nesse mesmo projeto. Isso porque, ao centrar o foco do processo formativo na unidade escolar, aquilo de que se trata é de capacitar o futuro pedagogo ao pleno domínio do funcionamento da escola. Assim, uma escola viva, funcionando em plenitude, implica um processo de gestão que garanta a presença de professores exercendo a docência de disciplinas articuladas numa estrutura curricular, em ação coordenada, supervisionada e avaliada à luz dos objetivos que se busca atingir. Ora, um aluno que é preparado para o exercício da docência assimilando os conhecimentos elementares que integram o currículo escolar; estudando a forma como esses conhecimentos são dosados, seqüenciados e coordenados ao longo do percurso das séries escolares; compreendendo o caráter integral do desenvolvimento da personalidade de cada aluno no processo de aprendizagem; e apreendendo o modo como as ações são planejadas e administradas, estará sendo capacitado, ao mesmo tempo, para assumir a docência, para coordenar e supervisionar a prática pedagógica, orientar o desenvolvimento dos alunos e planejar e administrar a escola; e, assegurada essa formação, estará também capacitado a inspecionar o funcionamento de outras escolas. Claro que, sobre a base dessa formação inicial, será recomendável que, de modo especial para exercer as referidas funções no âmbito dos sistemas de ensino, sejam feitos estudos de aprofundamento, aperfeiçoamento e especialização em nível de pós-graduação. (SAVIANI, 2008, p. 152-153). 
Nessa concepção que acabo de expor, tomar a docência na Educação Infantil e anos iniciais do Ensino Fundamental como base da formação do pedagogo significa que o especialista vai se formar educador aprendendo como se forma, como se educa, como se organiza o processo educativo; é nesse sentido que, se vou formar o educador que tem esse domínio, posso pensar a escola como uma unidade orgânica em que professores e educadores (os especialistas) estão numa inter-relação pedagógica. O que fazem essas pessoas é a prática de um novo currículo. O educador, o pedagogo, tem que ter domínio desse complexo. Se ele entra na escola e vivencia o contato das crianças desde a fase infantil até a fundamental, então está tendo domínio da docência como trabalho com as crianças, mas também de como a escola é organizada, como é dirigida e como é administrada. A administração do processo, a coordenação, pode ser pensada individualmente e no coletivo. Nesse sentido posso formar, ao mesmo tempo, o pedagogo e o professor para Educação Infantil e anos iniciais do Ensino Fundamental. Formar o bom administrador, o bom supervisor significa o mergulho nas questões da educação, da escola. Se a gente conseguisse recuperar, pela ênfase na história, o sentido do clássico, nós poderíamos chegar a um modelo formativo consistente. Com efeito, o clássico fornece um critério para se distinguir, na educação, o que é principal do que é secundário; o essencial, do acessório; o que é duradouro do que é efêmero; o que indica tendências estruturais daquilo que se reduz à esfera conjuntural. Por esse caminho nós podemos libertar a pedagogia e os pedagogos da quase irresistível atração pelas novidades, o que os torna presas fáceis de modismos e de propostas enganosas que surgem e se difundem com a aparência de grandes achados, mas que logo se desfazem como cortinas de fumaça sendo substituídas por novas ondas para onde os pedagogos passarão a flutuar. Hoje tudo é equivalente, tudo é considerado como igualmente importante. Como eu vou dar conta de tudo? Então, resulta inevitável o mote pós-moderno: deixa fluir.

Revista Perspectiva: De fato, as DCN indicam uma horizontalização, tudo é importante. Se formos pensar numa proposta curricular com base nessa horizontalidade, teremos uma formação inchada e corremos o risco de perder de vista o que seria essencial na formação docente. Um outro ponto que queríamos discutir com o senhor refere-se à perspectiva de pesquisa nas DCNP. Nestas diretrizes, por exemplo, ela está colada na prática pedagógica interna à sala de aula, distante, portanto, do modo como o senhor entende a docência. Nas DCNP a docência é alargada pelas funções que supõe, mas não pelo escopo da formação. Nesta perspectiva, como articula a concepção de conhecimento com a de produção do intelectual?

Dermeval Saviani: A pesquisa está no centro, porque quando digo que nosso papel na universidade e, especificamente, na Faculdade de Educação é receber 
os jovens e colocá-los num ambiente que lhes permita familiarizar-se com os clássicos, nesse mesmo processo eles estão aprendendo a conhecer, a interpretar, a pesquisar. Então, ao mesmo tempo em que estou formando o docente para a escola, estou formando os intelectuais para refletirem sobre a escola. Mas aí surge outro problema para o curso de pedagogia. A tarefa do educador é a formação humana. Mas a formação humana é algo muito complexo. Portanto, a formação do educador, isto é, daquele que será encarregado de formar os seres humanos, não pode ser de curta duração. Deverá, pois, necessariamente, ser organizada como um curso de longa duração. Para formar um médico levam-se seis anos aos quais se acrescenta o tempo de residência e de especialização. Conseqüentemente, para formar um educador cuja tarefa, a de cuidar de gente, é bem mais séria do que cuidar da saúde, é necessário um tempo bem maior do que aquele que tem sido destinado aos cursos de formação dos profissionais da educação. Mas aí nós esbarramos na desvalorização social da profissão, na orientação da política educacional que busca reduzir o tempo de formação e nas limitações orçamentárias decorrentes da visão produtivista, sempre empenhada na redução de custos e de investimentos na educação. Sem reverter essas tendências de modo a conferir à formação de educadores o lugar de destaque que lhe cabe na sociedade humana, o curso de pedagogia não terá um tratamento adequado e carregará indefinidamente a marca da precariedade.

\section{Notas}

1 Entrevista realizada por Olinda Evangelista, em 8 de agosto de 2006. Participaram Olga Durand, Suze Scalcon e Wilson Schmidt, professores da Universidade Federal de Santa Catarina - UFSC. Jocemara Triches, acadêmica de Pedagogia, transcreveu a fita.

2 Em 2006, o Conselho Pleno do Conselho Nacional de Educação aprovou a Resolução n ${ }^{\circ} 1 / 06$ que institui Diretrizes Curriculares Nacionais para o Curso de Pedagogia (BRASIL. CNE, 2006).

3 As Conferências Brasileiras de Educação - CBE - começaram a ser organizadas no Brasil em 1989. Constituíram-se em importante espaço de discussão teórica e luta política de educadores brasileiros em favor da educação pública. Em 1991 realizou-se a VI e última CBE. Às CBEs seguiram-se os Congressos Nacional de Educação, CONED. O I CONED reuniu mais de cinco mil participantes em Belo Horizonte, de 31 de julho a 3 de agosto de 1996. 
4 O governo Fernando Henrique Cardoso (FHC) começou em primeiro de Janeiro de 1995 (primeiro período) e encerrou em primeiro de Janeiro de 2003 (segundo período).

5 Paulo Renato Souza foi Ministro da Educação durante os oito anos do governo FHC e implementou a chamada "reforma dos anos 90".

6 Após a promulgação da Constituição de 1988, educadores se organizaram no Fórum Nacional em Defesa da Escola Pública para elaborar um projeto de Lei de Diretrizes e Bases da Educação Nacional - LDB, de acordo com o que rezava a Constituição. O primeiro projeto, de autoria do entrevistado, foi apresentado pelo então Deputado Federal, Otávio Elísio, antes Secretário de Estado da Educação de Minas Gerais durante o governo de Tancredo Neves.

7 A nova Lei da educação (LDB): trajetória, limites e perspectivas. (SAVIANI, 2006).

8 A primeira proposta do CNE, apresentada em março de 2005, indicava que o curso de Pedagogia formaria, exclusivamente, o professor para atuar na Educação Infantil e nos anos iniciais do Ensino Fundamental. O especialista seria formado em nível de pós-graduação e a formação seria aberta a qualquer licenciado. (BRASIL, 2005).

9 Helena de Freitas foi presidente da Associação Nacional pela Formação de Educadores - ANFOPE.

10 Entre as entidades que participaram das negociações com o CNE durante as discussões acerca das DCNP se destacaram a ANFOPE, a Associação Nacional de Pós-Graduação e Pesquisa em Educação - ANPEd, o Fórum de Diretores de Faculdades de Educação - FORUMDIR.

11 A Resolução aprovada pelo CNE recuou da transformação do curso de Pedagogia em uma licenciatura em sentido estrito, incorporando à formação do docente, a do gestor e a do pesquisador. Nesta Resolução, o conceito de docência compreende os três elementos referidos (BRASIL, 2006).

12 Nos anos de 1960 o Brasil passou por transformações importantes no campo educacional. Com o advento da Ditadura Militar, articulou-se uma reforma, em consonância com interesses norte-americanos, que 
lançou seus tentáculos primeiro sobre o Ensino Superior, com a Lei ${ }^{\circ}$ 5.540, de 28 de novembro de 1968 (BRASIL, 1968). Seguiu-se a ela a reforma do depois denominado Ensino de Primeiro e Segundo Graus, correspondentes ao anterior Ensino Primário e Médio, em dois ciclos, ginasial e colegial, Lei $\mathrm{n}^{\circ}$ 5.692, de 11 de agosto de 1971 (BRASIL, 1971). Estas leis concretizaram a concepção tecnicista de educação.

13 Esse texto foi incluído no livro Educação: do senso comum à consciência filosófica (SAVIANI, 2007, p. 65-75). [Nota do Autor - NA]

14 Trata-se do texto "Uma estratégia para a reformulação dos cursos de pedagogia e licenciatura: formar o especialista e o professor no educador. A formação do educador". (CADERNO DA ANDE, 1981).

15 Valnir Chagas, então membro do Conselho Federal de Educação, após a homologação da LDB 4.024/61 (BRASIL, [2000?]), foi relator dos Pareceres do CFE no ${ }^{\circ}$ 251/62 (BRASIL, 1963) e 252/69 (BRASIL, 1969) que regulamentou o Curso de Pedagogia.

16 O professor refere-se ao movimento escolanovista brasileiro, cuja predominância começou nos anos trinta e declinou em fins dos anos 50. Neste projeto, do qual fizeram parte intelectuais como Fernando de Azevedo, Anísio Teixeira e Lourenço Filho, não há menção a curso de Pedagogia.

17 O professor José Carlos Libâneo liderou, com outros intelectuais, elaboração do Manifesto dos Educadores Brasileiros (LIBÂNEO, 2005), difundido por meio eletrônico em Setembro de 2005. A posição do Manifesto era contrária à da ANFOPE e apoiadores, particularmente no que tange à atribuição do curso de Pedagogia.

18 Saviani e Marin (2007).

19 Esse livro resultou do projeto de pesquisa "O espaço acadêmico da pedagogia no Brasil: perspectiva histórica e teórica" que teve alguns de seus resultados antecipados no referido "tema em destaque" dos Cadernos de Pesquisa, depois consolidados no livro mencionado, lançado pela Editora Autores Associados em agosto de 2008 (SAVIANI, 2008).

20 Trata-se do texto Formação de professores: a experiência internacional sob o olhar brasileiro, em co-autoria com Pedro L. Goergen (SAVIANI; GOERGEN, 2000). 
21 O Curso Normal Superior foi criado para formar professores para a Educação Infantil e anos iniciais do Ensino Fundamental. Ele seria parte de Institutos Superiores de Educação (BRASIL, 1996). Essa proposição foi rechaçada pela comunidade acadêmica, entre outros motivos, porque interferiria na formação que vinha sendo desenvolvida nos cursos de Pedagogia.

22 O Decreto federal $n^{\circ} 19851$, de 11 de abril de 1931, (BRASIL, 1934) Estatutos das Universidades Brasileiras, previa que a criação de uma universidade deveria contar com três das seguintes unidades: Faculdade de Educação, Ciências e Letras, Faculdade de Direito, Faculdade de Medicina e Escola de Engenharia. O Art. $3^{\circ}$ rezava que havendo obediência aos preceitos gerais da lei, admitiam-se "variantes regionais". A Regulamentação do artigo $3^{\circ}$ do Decreto federal $n^{\circ} .19851$, de 11.04.31, rezava que seria "também facultado ao Governo do Estado constituir em unidade didaticamente autônoma qualquer uma das seções da Faculdade de Educação, Ciências e Letras, a que alude o parágrafo anterior".

23 Com base nos Estatutos de 1931, a USP criou a Faculdade de Filosofia, Ciências e Letras e incorporou o Instituto de Educação do Estado de São Paulo. A FFCL formava o Bacharel em áreas específicas e o IEUSP, mediante a realização do Curso de Formação do Professor Secundário, licenciava para o magistério. No IEUSP também se formava o professor primário. Em 1938, o governo de Ademar de Barros extinguiu o IEUSP. A área de Educação foi subsumida pela FFCL como Seção de Educação transformada, em 1939, em Seção de Pedagogia (EVANGELISTA, 2002).

24 Em 1935 Anísio Teixeira criou a Universidade do Distrito Federal e incorporou o Instituto de Educação do DF, denominando-o Escola de Educação. Criou também a Escola de Filosofia. A UDF foi extinta em 1938, no mesmo mês em que se extinguiu o IEUSP. Com esses atos, o governo de Getúlio Vargas encerrou, arbitrariamente, as duas experiências escolanovistas de formação docente no Brasil em nível superior. Nesse processo, em 1939, criou-se o Curso de Pedagogia, agora no interior das Faculdades de Filosofia (EVANGELISTA, 2002).

25 O professor refere-se ao Decreto-Lei n ${ }^{\circ}$.190, de 4/4/1939 (BRASIL, 1939). 
26 Pela Lei $n^{\circ} 5.692 / 71$ o Ensino de $2^{\circ}$ Grau era obrigatoriamente profissionalizante. O Curso Normal, por exemplo, passou a denominar-se Habilitação Magistério.

27 O Decreto n. 2.208, de 17 de abril de 1997 (BRASIL, 2009), que regulamentou os dispositivos da Lei n. 9.394/96 referentes à educação profissional, retirou o caráter profissionalizante do Ensino Médio.

28 Referência ao Decreto-lei n. 8.530, de 2 de janeiro de 1946 (BRASIL, 1946).

29 A legislação definiu as habilitações possíveis na formação do Pedagogo: Administração Escolar, Inspeção Escolar, Supervisão Escolar, Orientação Educacional. Vale mencionar que essas habilitações sofreram mudanças, desaparecendo algumas e sendo criadas outras, dependendo das políticas estaduais e municipais. Vale mencionar também que a formação para o magistério nos anos iniciais do Ensino Fundamental no interior do curso surgiu nos anos de 1980.

\section{Referências}

BRASIL. Decreto-lei n. 1.190, de 4 de abril de 1939. Dá organização à Faculdade Nacional de Filosofia. 1939. Diário Oficial da União: Seção 1, 6/4/1939 , Página 7929 (Publicação) .

BRASIL. Conselho Nacional de Educação. Conselho Pleno. Projeto de Resolução. Institui Diretrizes Curriculares Nacionais para os cursos de graduação em Pedagogia. Brasília, 2005.

BRASIL. Conselho Nacional de Educação. Conselho Pleno. Resolução $n^{\circ} 1$, de 15 de maio de 2006. Institui Diretrizes Curriculares Nacionais para o Curso de Graduação em Pedagogia, licenciatura. Brasília, 2006.

BRASIL. Ministério da Educação. Lei de Diretrizes e Bases da Educação Nacional n $n^{\circ}$ 9394/96 de 20 de dezembro de 1996. Estabelece as diretrizes e bases da educação nacional. Brasilia: MEC, 1996. Disponível em: <http:// www.mec.gov.br/legis/pdf/LDB.pdf.>. Acesso em: 17 jul. 2003.

BRASIL. Conselho Nacional de Educação. Conselho Pleno. Resolução $n^{\circ}$ 1, de 15 de maio de 2006. Institui Diretrizes Curriculares Nacionais para o Curso de Graduação em Pedagogia, licenciatura. Brasília, 2006. 
BRASIL. Conselho Federal de Educação. Parecer nº. 251/1962. Currículo mínimo e duração do curso de pedagogia. Relator: Valnir Chagas. Documenta, Brasília, n. 11, 1963.

BRASIL. Conselho Federal de Educação. Parecer no. 252/1969. Estudos pedagógicos superiores. Mínimos de conteúdos e duração para o curso de graduação em pedagogia. Relator: Valnir Chagas. Documenta, Brasília, n. 100, 1969.

BRASIL. Decreto federal Regulamentação do artigo $3^{\circ}$ do Decreto federal $n^{\circ} .19851$, de 11 de abril de 1931. In: DECRETOS Federais e Estaduais. São Paulo: Imprensa Oficial do Estado, 1934.

BRASIL. Decreto n. 2.208, de 17 de abril de 1997. Regulamenta o $\$ 2^{\circ}$ do art. 36 e os arts. 39 a 42 da Lei Federal no 9.394/96, que estabelece as Diretrizes e Bases da Educação Nacional. 1997. In: CENTRO de Referência Virtual do Professor. Minas Gerais, 2009. Disponível em: < http://crv.educacao.mg.gov.br/sistema_crv/banco_objetos_ crv/\%7B7206E114-49A8-4A64-B3F2-87DFAEF72210\%7D_ DF2208_97.pdf.>. Acesso em: 18 maio 2008.

BRASIL. Decreto-lei n. 8.530, de 2 de janeiro de 1946. Lei Orgânica do Ensino Normal. 1946. In: GOMES, Carlos A. M.; GOMES, Carlos M.; GOMES, Cristiano M. Soleis.adv.br.. [S.1., 2000?],Disponível em: < http:// www.soleis.adv.br/leiorganicaensinonormal.htm. $>$. Acesso em: 18 maio 2008.

BRASIL. Ministério da Educação. Lei Federal n. 5.540, de 28 de novembro de 1968. Fixa normas de organização e funcionamento do ensino superior e sua articulação com a escola média, e dá outras providências. Brasília, 1968. Disponível em: < http://www.planalto.gov.br/ccivil_03/Leis/ L5692.htm>. Acesso em: 21 jun. 2006.

BRASIL. Ministério da Educação. Lei no 5.692, de 11 de agosto de 1971. Fixa Diretrizes e Bases para o ensino de $1^{\circ}$ e $2^{\circ}$ graus, e dá outras providências. Brasília, 1971. Disponível em: <http://www.planalto.gov. br/ccivil_03/Leis/L5540.htm>. Acesso em: 21 jun. 2006.

BRASIL. Ministério de Estado da Educação e Saúde Pública. Decreto federal $n^{\circ}$ 19851, de 11 de abril de 1931, Estatutos das Universidades Brasileiras. Rio de Janeiro: Imprensa Nacional, 1931. 
BRASIL. Presidência da República.Casa Civil. Lei $n^{0} 4.024$, de 20 de dežembro de 1961. Fixa as Diretrizes e Bases da Educação Nacional. 1961. Brasilia, [2000?]. Disponível em: <http://www.planalto.gov.br/ccivil/ Leis/L4024.htm. >. Acesso em: 18 maio 2008.

EVANGELISTA, Olinda. A formação universitária do professor: o Instituto de Educação da Universidade de São Paulo (1934-1938). Florianópolis: NUP/CED/UFSC/ Editora Cidade Futura, 2002.

LIBÂNEO, José Carlos et al. Manifesto dos educadores brasileiros. São Paulo, 20 out. 2005. Mimeografado. Disponível em meio eletrônico em set. 2005.

SAVIANI, D. A nova lei da educação (LDB): trajetória, limites e perspectivas. 10. ed. Campinas: Autores Associados, 2006.

SAVIANI, D. Educação: do senso comum à consciência filosófica. 17. ed. Campinas: Autores Associados, 2007.

SAVIANI, D. A pedagogia no Brasil: história e teoria. Campinas: Autores Associados, 2008.

SAVIANI, D. Uma estratégia para a reformulação dos cursos de pedagogia e licenciatura: formar o especialista e o professor no educador. A formação do educador. Caderno da ANDE, Brasília, v. 1, n. 8, ago, 1982 , p.13-17.

SAVIANI, D.; GOERGEN, P. L. Formação de professores: a experiência internacional sob o olhar brasileiro. 2. ed. Campinas, SP: [s.n.], 2000.

SAVIANI, D.; MARIN, Alda J. Pedagogia. Cadernos de Pesquisa, Campinas, SP, v. 37, n. 130, p. 13-14, jan./abr. 2007. 


\section{Dermeval Saviani}

Universidade Estadual de Campinas

Faculdade de Educação, Departamento de Filosofia e História da Educação Rua Bertrand Russell, 801

Bairro: Barão Geraldo

CEP: 13081-970 - Campinas, SP

Caixa-Postal: 6120

URL da Homepage: http:/ / fae.unicamp.br/dermeval/ 